\title{
Hopping from One Cell to Another: Huntington's Disease Propagates
}

\author{
Sang Myun Park* \\ Department of Pharmacology, Ajou University School of Medicine, Suwon 16499, \\ Chronic Inflammatory Disease Research Center, Ajou University School of Medicine, Suwon 16499, \\ BK21 plus program, Department of Biological Sciences, Ajou University School of Medicine, Suwon 16499, Korea
}

Prion-like propagation of protein inclusions in many neurodegenerative diseases has received a great deal of attention. In this issue of Experimental Neurobiology, Kim et al. [1] describe a useful in vivo model for the cell-to-cell transmission of polyQ aggregates, which are associated with Huntington's disease in Caenorhabditis elegans (C. elegans) using bimolecular fluorescence complementation (BiFC) technique.

Millions of people suffer from progressive neurodegenerative diseases such as Alzheimer's disease (AD), Parkinson's disease (PD), and Huntington's disease (HD). Diagnosis and treatment of these diseases cost billions of dollars per year. Unfortunately, their pathogenesis still remain too elusive to allow the rational design of therapeutic interventions that should stop or reduce their progression. It has been established that they show the common pathological features of protein aggregate inclusions, although the main component of protein inclusions of each disease differs. AD shows extracellular senile plaques and cytosolic neurofibrillary tangles comprising mainly $\mathrm{A} \beta$ and hyperphsophorylated tau, respectively. PD shows cytosolic Lewy bodies or Lewy neurites composed of mainly a-synuclein. HD also shows nuclear protein inclusions composed of mainly mutated huntingtin with expanded polyQ. Furthermore, the process of protein inclusion formation has been considered to play a major role on the pathogenesis of many neurodegenerative diseases and become therapeutic targets for more than 2 decades [2]. Interestingly, recent research shows their regional and intercellular spreading irrespective of cytosolic

\footnotetext{
* To whom correspondence should be addressed. TEL: 82-31-219-5063, FAX: 82-31-219-5069 e-mail:sangmyun@ajou.ac.kr
}

or extracellular proteins and these processes are suspected to be significant in the pathogenesis of neurodegenerative diseases. In particular, intercellular spreading of cytosolic proteins such as hyperphosphorylated tau, $\boldsymbol{\alpha}$-synuclein, and mutated huntingtin has attracted much attention because it may provide mechanistic insights to the pathogenesis and motivational drive to develop novel therapeutic interventions such as blocking secretion and reuptake $[3,4]$.

Intercellular spreading of mutant huntingtin has been recently demonstrated in cell and mouse model systems [5]. Nevertheless, given that a variety of model systems complementing each other are critical to study the disease, Kim et al. [1] developed an in vivo model system in C. elegans to complement the cell and mouse model systems. They generated BiFC transgenic lines in which polyQ proteins are overexpressed in both pharyngeal muscles and neurons connected with the pharyngeal muscle in $C$. elegans and demonstrated that the transmission does occur between these two cell types and the lines with long polyQ exhibited stronger BiFC fluorescence than the lines with short polyQ, which correlated with degenerative phenotypes in an age dependent manner. BiFC is a widely used fluorescence technique that has been successfully applied to assess protein-protein interactions and protein dimerization and/or oligomerization in living cells. It has been already proved to be useful to study cell-to-cell transmission of protein aggregates such as tau [6] and $a$-synuclein [7]. In addition, the $C$. elegans has a relatively short life cycle ( $\sim 3.5$ days), fast reproduction cycle with a high progeny number $(\sim 300)$, short life span ( 2 weeks), which makes it applicable to a wide variety of highthroughput manipulations [8]. Accordingly, this system shows a high potential to be applied to a screening of genetic and chemical
Copyright $\odot$ Experimental Neurobiology 2017. www.enjournal.org
This is an Open Access article distributed under the terms of the Creative Commons Attribution Non-Commercial License (http://creativecommons.org/licenses/by-nc/4.0) which permits unrestricted non-commercial use, distribution, and reproduction in any medium, provided the original work is properly cited. 
modifiers of the propagation of polyQ proteins to complement the weaknesses of cell and mouse model systems.

Although prion-like propagation of protein inclusions has been attracted a great attention, there are still matters of controversy and many hurdles remain to be overcome $[9,10]$. Nevertheless, a variety of model systems including this system will be helpful to better understand the causes of diseases. Fortunately, the authors have already developed a similar in vivo model system to monitor cell-to-cell transmission of $\alpha$-synuclein [11], implying that a comparison between these two model systems make us understand the common and different features of these diseases, further uncovering the pathogenesis of various neurodegenerative diseases.

\section{REFERENCES}

1. Kim DK, Cho KW, Ahn WJ, Perez-Acuña D, Jeong H, Lee HJ, Lee SJ (2017) Cell-to-cell transmission of polyglutamine Aggregates in C. elegans. Exp Neurobiol (in press).

2. Agorogiannis EI, Agorogiannis GI, Papadimitriou A, Hadjigeorgiou GM (2004) Protein misfolding in neurodegenerative diseases. Neuropathol Appl Neurobiol 30:215-224.

3. Lee SJ, Desplats P, Sigurdson C, Tsigelny I, Masliah E (2010) Cell-to-cell transmission of non-prion protein aggregates. Nat Rev Neurol 6:702-706.

4. Stopschinski BE, Diamond MI (2017) The prion model for progression and diversity of neurodegenerative diseases. Lancet Neurol 16:323-332.
5. Pecho-Vrieseling E, Rieker C, Fuchs S, Bleckmann D, Esposito MS, Botta P, Goldstein C, Bernhard M, Galimberti I, Müller M, Lüthi A, Arber S, Bouwmeester T, van der Putten H, Di Giorgio FP (2014) Transneuronal propagation of mutant huntingtin contributes to non-cell autonomous pathology in neurons. Nat Neurosci 17:1064-1072.

6. Tak H, Haque MM, Kim MJ, Lee JH, Baik JH, Kim Y, Kim DJ, Grailhe R, Kim YK (2013) Bimolecular fluorescence complementation; lighting-up tau-tau interaction in living cells. PLoS One 8:e81682.

7. Outeiro TF, Putcha P, Tetzlaff JE, Spoelgen R, Koker M, Carvalho F, Hyman BT, McLean PJ (2008) Formation of toxic oligomeric alpha-synuclein species in living cells. PLoS One 3:e1867.

8. Nussbaum-Krammer CI, Morimoto RI (2014) Caenorhabditis elegans as a model system for studying non-cell-autonomous mechanisms in protein-misfolding diseases. Dis Model Mech 7:31-39.

9. Surmeier DJ, Obeso JA, Halliday GM (2017) Parkinson's disease is not simply a prion disorder. J Neurosci 37:9799-9807.

10. Brundin P, Melki R (2017) Prying into the prion hypothesis for Parkinson's disease. J Neurosci 37:9808-9818.

11. Kim DK, Lim HS, Kawasaki I, Shim YH, Vaikath NN, ElAgnaf OM, Lee HJ, Lee SJ (2016) Anti-aging treatments slow propagation of synucleinopathy by restoring lysosomal function. Autophagy 12:1849-1863. 